\title{
Aetiology
}

\section{Weekly urge urinary incontinence was associated with increased risk for falls and non-spinal fractures in older women} Brown JS, Vittinghoff E, Wyman JF, et al, for the Study of Osteoporotic Fractures Research Group. Urinary incontinence: does it
increase risk for falls and fractures? J Am Geriatr Soc 2000 Jul;48:721-5.

QUESTION: In community dwelling older white women, do urge and stress urinary incontinence increase risk for falls and non-spinal fractures?

Design

Cohort study with mean 3 year follow up (Study of Osteoporotic Fractures [SOF]).

\section{Setting}

4 clinical care centres in Maryland, Minnesota, Oregon, and Pennsylvania, USA.

\section{Participants}

6049 community dwelling, ambulatory white women who were $\geqslant 65$ years of age (mean age $79 \mathrm{y}$ ), attended 5 SOF clinic or home visits, completed a physical examination and self administered questionnaire, provided data on urinary incontinence, and returned $\geqslant 1$ postcard reporting falls after visit 5 .

\section{Assessment of risk factors}

Number of live births; hysterectomy status; smoking status; alcohol use; walking; total weekly excursions outside the home; medical history, including hip or knee replacement, stroke, diabetes, Parkinson' or Alzheimer' disease, or arthritis; self reported joint pain; falls within the past year; functional status; medication use; and cognitive function. Frequency and type (urge, stress, or mixed) of urinary incontinence were assessed at the fifth clinic visit.

\section{Main outcome measures}

Reported falls and nonspinal, nontraumatic fractures (fractures were confirmed by radiography).

\section{Main results}

$25 \%$ of women reported $\geqslant 1$ weekly episode of urge incontinence, and 19\% reported $\geqslant 1$ weekly episode of stress incontinence; $12 \%$ reported both types of incontinence. Women with no incontinence or less than weekly incontinence formed the control group. $55 \%$ of women reported $\geqslant 1$ fall during the mean 3 year follow up, and $8.5 \%$ reported $\geqslant 1$ fracture. After adjusting for age and other potential confounding factors, urge incontinence was associated with falls $(p<0.001)$ and fractures $(p=0.02)$, whereas stress incontinence was not $(p \geqslant 0.3)$ (table).

\section{Conclusion}

In community dwelling older white women, weekly or more frequent urge but not stress urinary incontinence increased the risk for falls and non-spinal fractures.

*Not significant.

Source of funding: in part, National Institute on Ageing.

For correspondence: DrJ $S$ Brown, Department of Obstetrics, Gynaecology, and Reproductive Sciences, University of California, San Francisco, 2330 Post Street, Suite 220, San Francisco, CA 94115 , USA.Fax + 1415353 9509.

A modified version of this abstract also

appears in

Evidence-Based

Nursing.

Risk for falls and non-spinal fractures in women with $\geqslant$ weekly urinary incontinence at mean 3 year follow up

\begin{tabular}{lll} 
Outcomes & Type of incontinence & Adjusted odds ratio $(95 \% \mathrm{Cl})$ \\
\hline Falls & Urge & $1.26(1.14$ to 1.40$)$ \\
\hline & Stress & $1.06(0.95 \text { to } 1.19)^{\star}$ \\
\hline & & Relative hazard $(\mathrm{Cl})$ \\
\hline Fractures & Urge & $1.34(1.06$ to 1.69$)$ \\
\hline & Stress & $0.98(0.75 \text { to } 1.28)^{\star}$ \\
\hline${ }^{*}$ Not significant. &
\end{tabular}

\section{COMMENTARY}

The study by Brown $e t a l$ is part of the larger SOF, a US cohort study of community dwelling elderly women. In this report, data collected at the time of the fifth follow up visit were examined to determine whether urinary urge and stress incontinence were independent risk factors for falls and fractures. The results show a small but statistically significant increase in risk for falls and fractures from urge but not stress incontinence. From a methodological standpoint, the study is strong: it included a defined, representative sample of patients; follow up was sufficiently long; and outcome criteria (fractures) were objective. Multivariate analyses were done, adjusting for several known prognostic factors, including age, use of sedative medication, frailty, relevant medical problems, and gait and balance abnormalities. ${ }^{1}$ Missing from the multivariate analysis was adjustment for cognitive impairment, and because urge incontinence is often present in patients with subcortical dementia, this omission may be relevant. It is also possible that medication used to treat incontinence (eg, anticholinergic agents) contributed to the falls. The fact that a dose response curve existed with patients who noted more frequent (ie, daily) urge incontinence having a higher risk for falls (35\%) than patients with weekly incontinence (21\%) supports an aetiological association.

It is premature to speculate about the clinical significance of the findings of this study, other than as another, perhaps unexpected, risk factor for falls. Tinetti $e t$ al showed that falls have many causes and that treating some of these contributing factors decreases the risk for falling. ${ }^{2}$ If incontinence is validated as a risk factor for falls and fractures in an independent group (test set) of patients, then treatment of urge incontinence could be evaluated for the possible added benefit of preventing falls.

Suzanne D Fields, MD

State University of New York at Stony Brook, Stomy Brook, New York, USA

1 Tinetti ME, Doucette J, Claus E, et al. Risk factors for serious injury during falls by older persons in the community. J Am Geriatr Soc. 1995;43:1214-21.

2 Tinetti ME, Baker DI, McAvay G, et al. A multifactorial intervention to reduce the risk of falling among elderly people living in the community. N Engl J Med 1994;331:821-7. 